\title{
7 Combined Fluorescent and Gold Probes for Microscopic and Morphological Investigations
}

\author{
Richard D. Powell and James F. Hainfeld
}

\section{INTRODUCTION}

Nanogold ${ }^{\circledR}$, a gold cluster with a core of gold atoms $1.4 \mathrm{~nm}$ in diameter, has proven to be a superior probe label for electron microscopy (EM), 14,17 giving both higher labeling density 28,31 and improved access to previously hindered or restricted antigens. ${ }^{29,31}$ It may be visualized by autometallography (AMG) for use in light microscopy (LM): silver-and gold-amplified Nanogold detection ${ }^{12,18}$ has proven to be one of the most sensitive methods available for the detection of low copy number targets such as viral DNA in cells and tissue specimens. ${ }^{32}$ AMG enhancement has also made Nanogold an effective detection label in blots ${ }^{15}$ and gels. ${ }^{10}$ The following protocols will be described:

- Labeling of nuclear components in cells.

- Protocol for in situ hybridization and detection with fluorescein-Nanogoldor $\mathrm{Cy} 3^{\mathrm{TM}}-\mathrm{Nanogold}$-labeled streptávidin.

Nanogold is an inert molecule, and gencrally does not interact with biological molecules unless a specific chemical reactivity is introduced into the molecule. Conjugates are prepared using site-specific chemical conjugation through reactive chemical functionalities introduced during Nanogold preparation, which allows the gold label to be attached to a specific site on the conjugate biomolecule. For example, a maleimido-Nanogold derivative, which is specific for thiol binding, is frequently attached to the hinge region of an antibody at a unique thiol site generated by selective reduction of a hinge disulfide. ${ }^{14}$ This site is remote from the antigen combining region, and the Nanogold, therefore, does not compromise target binding. Nanogold may also be prepared with specific reactivity towards amines 27 or other unique chemical groups.

This mode of attachment enables the preparation of probes labeled with both Nanogold and fluorescent labels. Different chemical reactivities are used to attach the Nanogold and the fluorescent groups to different sites in the conjugate biomolecule, as shown in Figure 7.1. In this manner, the two labels are spaced sufficiently far apart that fluorescent resonance energy 
transfer ${ }^{8,21}$ does not quench the fluorescent signal, and the probes may be used to label specimens for fluorescent and EM observation in a single staining procedure. ${ }^{23,26}$ This reduces the complexity of the staining procedure, allowing less specimen perturbation, and also enables a higher degree of correlation between the fluorescence and EM localization of the target, ${ }^{30}$ thus increasing the usefulness of the complementary data sets.

Since gold and fluorescent-labeled probes are often used at different concentrations under different conditions, optimum procedures for the use of fluorescent and gold probes may entail some degree of compromise between the most appropriate conditions for the two types of probes. However, the chemical stability of the Nanogold label means that it is generally stable to a wide range of use conditions, and the following protocols have been found to be effective for labeling specimens with combined fluorescein and Nanogold-labeled antibody Fab' probes and with combined $\mathrm{Cy} 3$ and Nanogold-labeled streptavidin.

\section{PROTOCOLS}

Protocol 1. Immunoabeling of Cellular

Components, after Spector ${ }^{23}$

\section{Materials and Reagents}

- Phosphate-buffered saline (PBS): 0.02 $\mathrm{mol} / \mathrm{L}$ sodium phosphate buffer with $0.15 \mathrm{~mol} / \mathrm{L}$ sodium chloride, $\mathrm{pH}$ adjusted to 7.6 .

- Normal goat serum (NGS).

- Fluorescein and Nanogold-labeled Fab' (FluoroNanogold) conjugate (Nanoprobes, Yaphank, NY, USA).

- Glutaraldehyde.

- $0.02 \mathrm{~mol} / \mathrm{L}$ sodium citrate buffer, $\mathrm{pH}$ 7.0 .

- HQ Silver enhancement kit (Nanoprobes).

- Hydrofluoric acid (37\% or $40 \%$ aqueous).

- Neutralizing solutions for hydrofluoric acid. Dissolve one heaped spoonful of each into water in numbered 100 $\mathrm{mL}$ plastic tripour beakers:

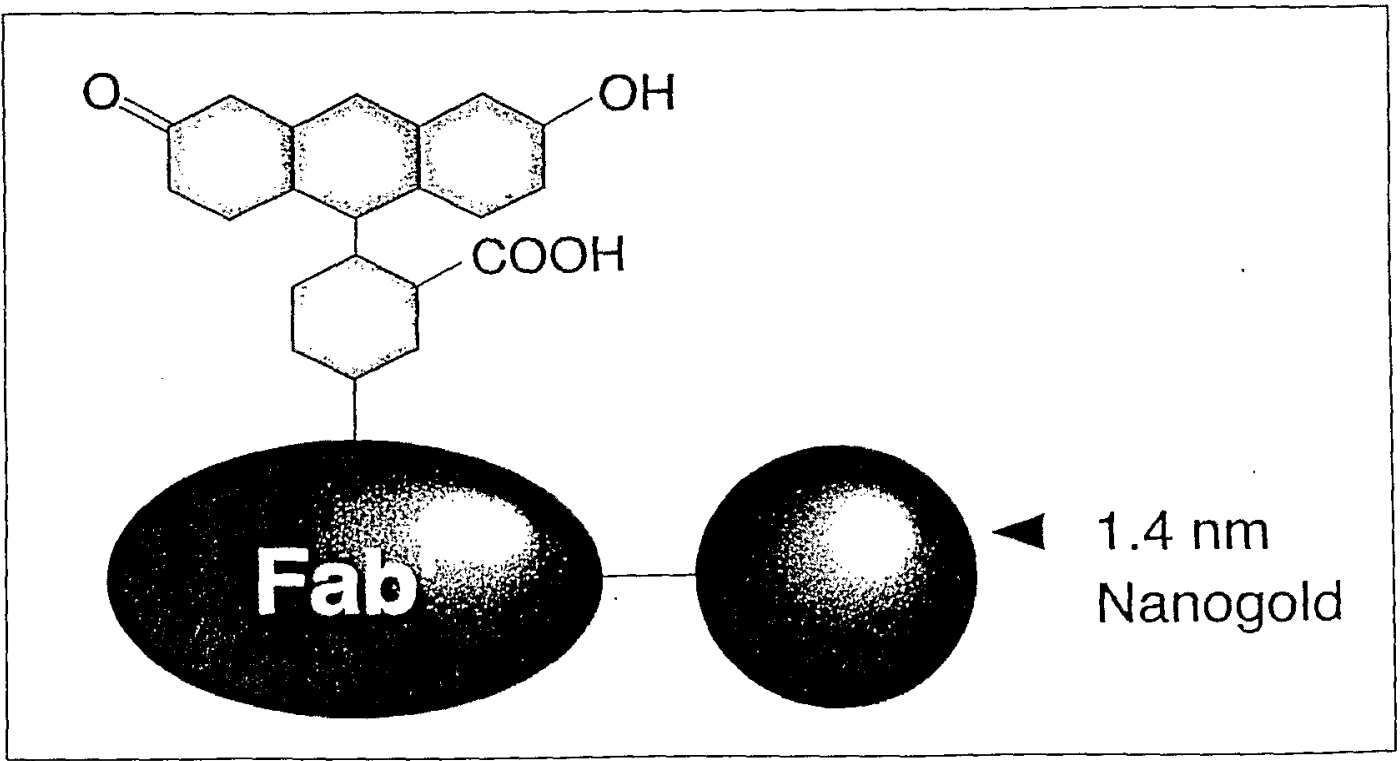

Figure 7.1. Structure of combined fuorescein and Nanogold probe. This novel reagent is prepared by sequential conjugation of Nanogold followed by fluorescein. 
1. Converter for hydrofluoric acid; magnesium sulfate.

2. Neutralizer for acids; sodium carbonate.

- Uranyl acetate.

- Reynolds lead citrate: place lead nitrate, $\mathrm{Pb}\left(\mathrm{NO}_{3}\right)_{2}(1.33 \mathrm{~g})$, trisodium citrate dihydrate, $\mathrm{Na}_{3}\left(\mathrm{C}_{6} \mathrm{H}_{5} \mathrm{O}_{7}\right) \cdot 2 \mathrm{H}_{2} \mathrm{O}(1.76$ $\mathrm{g}$ ), and $30 \mathrm{~mL}$ of distilled water in a 50 $\mathrm{mL}$ volumetric flask, shake vigorously for $1 \mathrm{~min}$, and allow to stand for 30 min with occasional shaking to ensure complete conversion of lead nitrate to lead citrate before use. ${ }^{24}$

\section{Staining Procedure}

1. Grow HeLa cells on coverslips for two days. Fix, wash, and permeabilize. ${ }^{9}$

2. Incubate cells with primary antibody at appropriate dilution for $1 \mathrm{~h}$ (diluted in PBS containing $0.1 \%$ NGS).

3. Wash in PBS containing 1\% NGS.

4. Incubate with a 1:10 dilution of fluorescein-Nanogold-conjugated Fab' secondary antibody probe for $1 \mathrm{~h}$ at room temperature. At this point, fluorescence photomicrographs may be acquired.

5. Wash cells with PBS.

6. Fix in $1 \%$ glutaraldehyde in PBS for 15 min.

7.Wash with PBS (3 time for $10 \mathrm{~min}$ ). Prior to silver enhancement, change the buffer to $0.02 \mathrm{M}$ sodium citrate buffer, $\mathrm{pH}$ 7.0. Wash cells extensively in this buffer (chlorides must be removed before silver enhancement).

8. Perform the silver enhancement procedure in the darkroom using a Thomas Duplex sodium vapor or equivalent safelight. HQ Silver may be used to enhance the gold probe in the cells. Prepare HQ Silver by vortex mixing a 1:1:1 mixture of initiator, moderator, and activator. Dry the backs of the coverslips using filter paper, and apply $200 \mu \mathrm{L}$ of the silver enhancement solution to the cell side of the coverslip. After approximately $15 \mathrm{~min}$, or when the silver changes from clear to gray, wash it off the coverslip using citrate buffer.

9. Once silver enhancement is complete, wash the cells extensively with citrate buffer to remove any nonspecific silver deposits and to prevent any further silver enhancement.

10. Dehydrate cells through a graded series of ethanol. Infiltrate with a 50:50 solution of ethanol and Epon-Araldite (Electron Microscopy Sciences, Fort Washington, PA, USA) for $18 \mathrm{~h}$, followed by $100 \%$ Epon-Araldite for $8 \mathrm{~h}$. Embed coverslips in Epon-Araldite and place in an oven at $60^{\circ} \mathrm{C}$ for $48 \mathrm{~h}$ to polymerize.

11. Remove the glass coverslips using hydrofluoric acid (see Addendum below).

12. Section the embedded cells and pick up on 200 mesh copper grids.

13. Counterstain with $5 \%$ uranyl acetate for $5 \mathrm{~min}$.

14. Stain with Reynolds lead citrate 24 for 1 min; sections may also be regressed by floating on $0.2 \mathrm{M}$ EDTA in distilled water for $30 \mathrm{~min}$ between the uranyl acetate and lead citrate staining. ${ }^{4}$

15. View with transmission EM operated at $75 \mathrm{kV}$.

Protocol Addendum: Removing Coverslips with Hydrofluoric Acid

Caution: Hydrofluoric acid is extremely dangerous. Always handle in a fume hood. Keep neutralizing solutions (see below) handy. Use laboratory coat, goggles, and double gloves (nitrile or rubber if at all possible). 


\section{Procedure}

1. Remove excess resin from bottom of coverslip by scraping with a razor blade. Wipe with an acetone-soaked cotton swab to remove all the resin. The glass has to be completely clean or glass slivers will be left on the face of your blocks after removal.

2. Use half of a $35 \mathrm{~mm}$ tissue culture dish for each coverslip. Place these on the Teflon ${ }^{\circledR}$ sheet in the fume hood and put the blocks into the $35 \mathrm{~mm}$ dish halves, coverslip side up.

3. Set up two more $100 \mathrm{~mL}$ plastic beakers with deionized water and put on laboratory coat, goggles, and gloves. You need to double glove; use nitrile or rubber gloves if at all possible. Also have kimwipes, water bottle, forceps, and plastic transfer pipet in the hood.

4. Use a plastic transfer pipet to add hydrofluoric acid dropwise to the coverslips. Fifteen to 20 drops per coverslip is usually plenty. Let sit for $10 \mathrm{~min}$. If the hydrofluoric acid runs over the edge, turn the coverslip over and float it on pool of hydrofluoric acid in the dish.

5. After $10 \mathrm{~min}$, pick up coverslip with forceps and dip in beaker 1 , then in beaker 2 , then rinse with water, and dry with kimwipes. The glass will probably only be etched after the first exposure to hydrofluoric acid. Repeat steps 4 and 5 until the glass is completely removed. Gridded coverslips tend to take longer to remove than do regular coverslips.

6. Put the plastic sample blocks in a plastic beaker and wash for $2 \mathrm{~h}$ with at least 3 changes of water.

7. Dishes, forceps, and pipets exposed to hydrofluoric acid are rinsed through 1 , then 2, and then in another beaker of water to rinse extensively before being disposed of as solid waste. Make sure you have not splashed acid on the teflon sheet. If you have, neutralize with a few drops of solutions 1, then 2, then wash with water. Dump solutions 1 and 2 down the sink and wash with running water at least $15 \mathrm{~min}$ apart so that they do not react. Wipe the Teflon sheet before storing.

An example of labeling using this method is shown in Figures 7.2 and 7.3, in which a monoclonal primary antibody followed by combined fluorescein and Nanogoldlabeled $\mathrm{Fab}^{\prime}$ secondary have been used to label the pre-mRNA splicing factor SC35 in HeLa cells.

Protocol 2. In Situ Hybridization and Detection with Fluorescein-Nanogoldor Cy3-Nanogold-Labeled Streptavidin

Protocols 2 and 3 were developed by $C$. Hauser-Kronberger and G.W. Hacker and co-workers (Salzburg) using combined Cy3 and Nanogold-labeled streptavidin, ${ }^{24}$ but are also effective with fluorescein and Nanogold-labeled streptavidin. They are based on their method developed for in situ hybridization detection with Nanogold ${ }^{\circledR} .12,32$

\section{Materials and Reagents}

- PBS: $10 \times \mathrm{PBS}\left(\mathrm{Mg}^{2+}\right.$ and $\mathrm{Ca}^{2+}$ free), $\mathrm{pH}$ 7.6: $11.36 \mathrm{~g} \mathrm{Na}_{2} \mathrm{HPO}_{4}, 2.72 \mathrm{~g}$ $\mathrm{KH}_{2} \mathrm{PO}_{4}, 87.0 \mathrm{~g} \mathrm{NaCl}$ in $800 \mathrm{~mL}$ distilled water. Adjust $\mathrm{pH}$ with concentrated $\mathrm{NaOH}$ and add distilled water to a final volume of $1 \mathrm{~L}$.

- Standard sodium citrate buffer (SSC): $175.32 \mathrm{~g} \mathrm{NaCl}$ and $88.23 \mathrm{~g}$ sodium citrate in $800 \mathrm{~mL}$ distilled water. Adjust $\mathrm{pH}$ with $\mathrm{NaOH}$ to 7.0 and add distilled water to a final volume of $1 \mathrm{~L}$.

- Prehybridization buffer: 50\% deionized formamide $10 \%$ dextran sulfate in $2 \times$ SSC.

- Lugol's iodine (Cat. No. L-6146; Merck, Darmstadt, Germany).

- Gelatin (45\%): Cold Water Fish 
Gelatin (Cat. No. G-7765; SigmaAldrich, Steinheim, Germany).

- Fluorescein-Nanogold- or Cy3-Nanogold-labeled streptavidin (Nanoprobes).

- Silver acetate AMG reagents (see below).

- Reagent grade alcohols.

- Ultrapure water.

- Proteinase K (Cat. No. 1373196; Roche Molecular Biochemicals, Mannheim, Germany).

- Biotinylated DNA probe (e.g., Enzo, New York, NY, USA).

- Coplin jars or equivalents.

- Standard laboratory pipettors.

- Slide warmers and/or incubators $\left(37^{\circ}\right.$ and $50^{\circ} \mathrm{C}$ capable).

- Heating block $\left(92^{\circ}-95^{\circ} \mathrm{C}\right.$ capable).

- Nuclear stains.

- Mounting media: Permount ${ }^{\mathrm{TM}}$ or DPX $^{\mathrm{TM}}$ (BDH Chemicals, Poole, England, UK).

\section{Staining Procedure}

1. Deparaffinize sections from formaldehyde-fixed tissue in fresh xylene (2 times for 15 min each).

2. Rinse and rehydrate in graded alcohols and distilled water (2-3 min each).

3. Soak in PBS (20 mmol/L, $\mathrm{pH} 7.6)$ for $3 \mathrm{~min}$.

4. Incubate with $0.1 \mathrm{mg} / \mathrm{mL}$ proteinase $\mathrm{K}$ in $\mathrm{PBS}$ at $37^{\circ} \mathrm{C}$ for about $8 \mathrm{~min}$. The duration is critical and has to be tested very carefully, depending on tissue, fixation, and other factors.

5. Rinse in 2 changes of PBS, for $3 \mathrm{~min}$.

6. Permeabilize with $0.3 \%$ Triton ${ }^{\circledR} \mathrm{X}-100$ in PBS for $15 \mathrm{~min}$.

7. Wash in PBS for $2 \mathrm{~min}$.

8. Rinse in 2 changes of distilled water, dehydrate with graded alcohols $(50 \%$, $70 \%$, and $98 \%$ isopropanol) for $1 \mathrm{~min}$ each, and air-dry the sections.

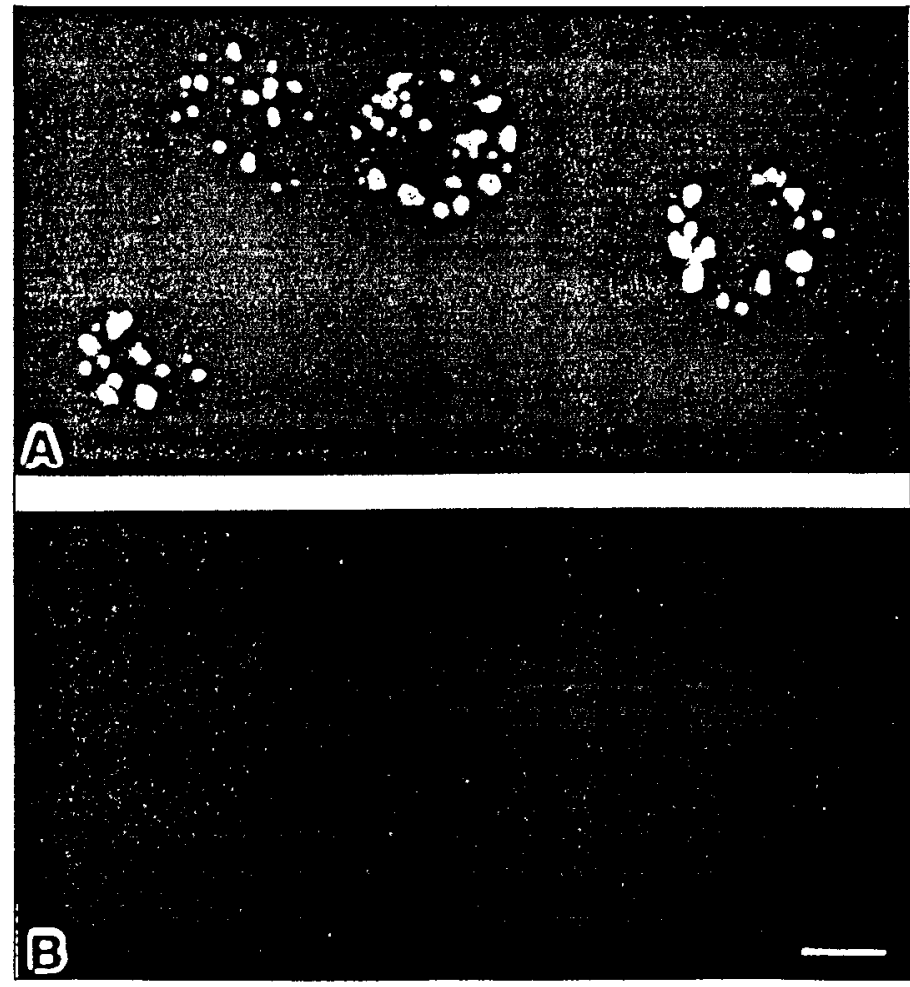

Figure 7.2. HeLa cells. Fluorescence photomicrographs of labeled HcLa cclls (A) stained with monoclonal primary antilody against SC35 pre-mRNA splicing factor, followed by secondary fluorescein and Nanogold-labeled antimouse Fab'. (B) Control staincd with fluorescein and Nanogold-labeled antimouse Fab' only (primary antibody omitced). Final original magnification $=1000 \times$, bar $=10 \mu \mathrm{m}$. (Reproduced with permission from Powell, R.D. et al., 1997, J. Histochem. Cytochem., 45:947-956.) 
9. Prehybridize with 1:1 mixture of deionized formamide and $20 \%$ dextran sulfate in $2 \times S S C$ at $50^{\circ} \mathrm{C}$ for $5 \mathrm{~min}$.

10. Carefully shake off excess prehybridization block.

11. Add one drop of biotinylated DNA probe on the section and cover with a small coverslip. Avoid air bubbles.

12. Heat sections on heating block at $92^{\circ}-94^{\circ} \mathrm{C}$ for 8 to $10 \mathrm{~min}$ to denature DNA.

13. Incubate in a moist chamber at $37^{\circ} \mathrm{C}$ overnight (or for at least $2 \mathrm{~h}$ ).

14. Posthybridization washes ( 5 min each): 2 changes of $4 \times$ SSC (first wash to remove coverslips), $2 \times$ SSC, $0.1 \times$ SSC, $0.05 \times$ SSC, and then distilled water.

15. Put slides into Lugol's iodine solution for 5 min.

16. Wash in tap water and then distilled water.
17. Put into $2.5 \%$ sodium thiosulfate for a few seconds until sections are colorless. Then wash in tap water for $5 \mathrm{~min}$ and distilled water for $2 \mathrm{~min}$.

18. Immerse in PBS containing $0.1 \%$ fish gelatin ( $45 \%$ concentrate) and $0.1 \%$ Tween ${ }^{\circledR} 20$ for 5 min.

19. Incubate sections with fluoresceinNanogold- or Cy3-Nanogold-labeled streptavidin diluted 1:200 to $1: 500$ in PBS containing $1 \%$ bovine serum albumin (BSA) at room temperature for $60 \mathrm{~min}$.

20. Wash in 3 changes of PBS containing $0.1 \%$ fish gelatin and $0.1 \%$ Tween 20 for 5 min each.

21. Repeatedly wash in distilled water for at least $10 \mathrm{~min}$ altogether, the last 2 rinses in ultrapure water (EM grade).

22. Perform silver acetate AMG (see Addendum) or GoldEnhance develop-

Figure 7.3. Transmission clectron micrographs of labeled Hela cells. (A) Cells stained with monoclonal primary antibody against SC35 pre-mRNA splicing factor, followed by secondary fluoresecin and Nanogold-labeled antimouse lab'. (B) Control stained with fluorescein and Nanogold-labcled ancimouse Fab' only (primary aniloody omitted). Bar $=1 \mu \mathrm{m}$. (Final manification $\times 12,000$.) (Reproduced with permission from Powcll, R.D. et al., 1997. J. Histochem. Cytochem., 45:947-956.)

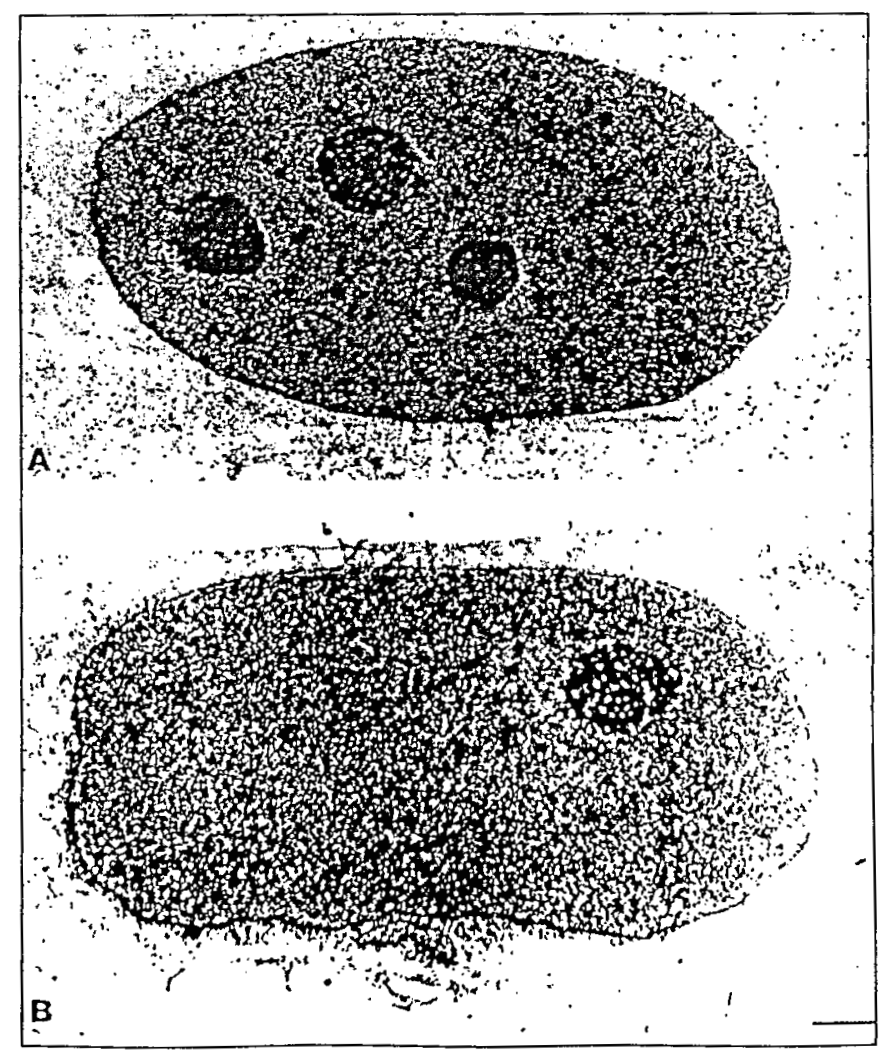


ment (Nanoprobes; see also Chapter 3).

23. Rinse carefully in tap water for at least 3 min. After silver amplification, sections can be counterstained with nuclear fast red, dehydrated, and mounted in Permount or in DPX. Do not use Eukitt (Electron Microscopy Sciences; this can change the intensity of silver stains after optimal development, sometimes even after weeks and months).

Protocol 3. In Situ Hybridization, Tyramide Signal Amplification and Detection with Combined Fluorescein-Nanogold- or Cy3Nanogold-Labeled Streptavidin

\section{Materials and Reagents}

This procedure will require the same materials, reagents, and equipment used for in situ hybridization detection (see Protocol 2). Tyramide signal amplification will additionally require the following

- Hydrogen peroxide.

- Methanol.

- Twreen 20.

- Dimethyl sulfoxide (DMSO).

- Fluorescein isothiocytrate (FITC) or biotin haptenated probe.

- GenPoint ${ }^{\mathrm{TM}}$ in situ streptavidin-biotinperoxidase complex kit (DAKO, Glostrup, DK, and Carpinteria, CA, USA), which includes blocking powder and biotinylated tyramide.

\section{Staining Procedure}

1. Deparaffinize sections from formaldehydc-fixed tissue in fresh xylenc ( 2 times for $15 \mathrm{~min}$ each).

2. Rinse in absolute ethanol ( 2 times for 5 min each), then $95 \%$ ethanol (2 times for 5 min each), followed by 2 changes of double-distilled water.

3. Immerse the slides in Target Retrieval solution (Cat. No. S1700; DAKO) at $95^{\circ} \mathrm{C}$ for $40 \mathrm{~min}$, then let the slides cool in the same solution for $20 \mathrm{~min}$.

4. Rinse the slides in several changes of double-distilled water, then incubate them with proteinase $\mathrm{K}$ (Cat. No. S3004; Dako) diluted 1:5000 in 50 $\mathrm{mmol} / \mathrm{L}$ Tris-HCl buffer (pH 7.6) for 5 min at room temperature. Alternatively, steps 3 and 4 may be replaced by pretreatment with $0.1 \mathrm{mg} / \mathrm{mL}$ proteinase $\mathrm{K}$ in $50 \mathrm{mmol} / \mathrm{L}$ Tris-HCl buffer ( $\mathrm{pH}$ 7.6) at $37^{\circ} \mathrm{C}$ for about $8 \mathrm{~min}$ (optimal duration should be tested).

5. Wash slides in double-distilled water (3 changes for $5 \mathrm{~min}$ each).

6. Treat with $3 \% \mathrm{H}_{2} \mathrm{O}_{2}$ in methanol at room temperature for $30 \mathrm{~min}$.

7. Wash slides in double-distilled water for $10 \mathrm{~min}$.

8. Put slides into Lugol's iodine solution for $5 \mathrm{~min}$, then wash in double-distilled water.

9. Put into $2.5 \%$ sodium thiosulfate for a few seconds until sections are colorless, then wash in double-distilled water (2 times for 5 min each).

10.Allow slides to air-dry.

11.Add one drop of biotinylated DNA probe on the section and cover with a small glass coverslip. Avoid air bubbles.

12. Heat sections on heating block at $92^{\circ}$ to $94^{\circ} \mathrm{C}$ for $5 \mathrm{~min}$ to denature DNA.

13. Incubate in a moist chamber at $37^{\circ} \mathrm{C}$ overnight (or for at least $1 \mathrm{~h}$ ).

14. Remove the coverslip by soaking slides in a TBST (Tris-buffered saline containing Tween 20) bath for 5 min.

15. Incubate slides in Stringent Wash (provided in the GenPoint kit) for 20 min at $55^{\circ} \mathrm{C}$.

16. Drain off section, wipe area around section dry, and surround it with a PAP-pen (Dako-Pen) (Cat. No. S-2002; Dako).

17. Immerse slides in TBST for $5 \mathrm{~min}$. 
18. Apply primary streptavidin-horseradish peroxidase (HRP), diluted $1: 800$ in the diluent (from GenPoint kit) to sections and incubate in a moist chamber for $15 \mathrm{~min}$ at room temperature.

19. Wash in 3 changes of TBST for 5 min each.

20.Apply ready-to-use biotinyl-tyramide solution (from GenPoint kit) and incubate in a moist chamber for $15 \mathrm{~min}$ at room temperature.

21. Wash in 3 changes of TBST-gelatin (TBST containing $0.1 \%$ fish gelatin $\mathrm{pH}$ 7.6) for 5 min each.

22.Incubate the sections with fluoresceinNanogold- or Cy3-Nanogold-labeled streptavidin diluted 1:250 in PBS containing $1 \% \mathrm{BSA}$ at room temperature for $60 \mathrm{~min}$.

23. Wash in 3 changes of TBST-gelatin for 5 min each.

24.Repeatedly wash in ultrapure water (EM grade).

25.Perform silver acetate AMG or GoldEnhance development according to the instructions of the manufacturer.

Note: The development process may be stopped by simply washing the sections in distilled water (several changes), or more effectively by a brief wash in $2 \%-5 \%$ sodium thiosulfate, followed by water.

26.After AMG amplification, sections can be counterstained with hematoxilin and eosin and/or nuclear fast red, dehydrated, and mounted in Permount or in DPX. Avoid the use of Eukitt. This can change the intensity of silver stains after optimal development, sometimes even after weeks and months.

\section{Protocol Addendum: Silver Acetate Autometallography ${ }^{12}$}

The procedure described here was modified for use with Nanogold reagents.

\section{Materials and Reagents}

- Solutions A and B should be freshly prepared for every run.

Solution A: Dissolve $80 \mathrm{mg}$ silver acetate (85140; Fluka, Buchs, Switzerland) in $40 \mathrm{~mL}$ of glass double-distilled water. Silver acetate crystals can be dissolved by continuous stirring within about 15 min.

- Citrate buffer: Dissolve $23.5 \mathrm{~g}$ of trisodium citrate dihydrate and $25.5 \mathrm{~g}$ citric acid monohydrate in $850 \mathrm{~mL}$ of deionized or distilled water. This buffer can be kept at $4^{\circ} \mathrm{C}$ for at least 2 to 3 weeks. Before use, adjust to $\mathrm{pH}$ 3.8 with citric acid solution.

- Solution B: Dissolve $200 \mathrm{mg}$ hydroquinone in $40 \mathrm{~mL}$ citrate buffer.

- Enhancement solution: Just before use, mix solution $A$ with solution $B$.

\section{Staining Procedure}

1. Silver amplification: Place the slides vertically in a glass container (preferably with about $80 \mathrm{~mL}$ volume and up to 19 slides; Schiefferdecker-type) and cover them with the mixture of solutions $A$ and $B$. Staining intensity can be checked in the LM during the amplification process, which usually takes about 5 to $20 \mathrm{~min}$, depending on primary antibody or nucleic acid probe concentration, incubation conditions, and the amount of accessible antigen or nucleic acid sequence in question.

2. Stop enhancement by washing in distilled water (several changes).

3. After stopping the enhancement process, slides can be examined in an LM more carefully. If staining intensity is still too low, wash slides for one more time in double-distilled water and develop further in enhancement solution.

Figure 7.4 shows two examples of the 
results obtained by this method. In this specimen, human papillomavirus type 16 (HPV-16) DNA is visualized in CaSki cells and in SiHa cells; the latter are known to contain only 1 to 2 copies of the target DNA, and the staining is clearly visualized by both fluorescence and LM.

\section{TECHNICAL HINTS AND DISCUSSION}

The optimum conditions for labeling with combined fluorescent and Nanogold probes generally will be close to those for using Nanogold probes in similar procedures, and this should be used as the starting point when using the combined fluorescent and Nanogold probes. The protocols above are intended as guidelines. Combined fluorescent and Nanogold probes are entirely covalently linked and stabilized. Therefore, the problems sometimes found with colloidal gold probes, which include aggregation leading to poor antigen access, 13 nonspecific binding, ${ }^{3}$ and probe dissociation, which gives rise to lower labeling, ${ }^{19}$ will usually be greatly

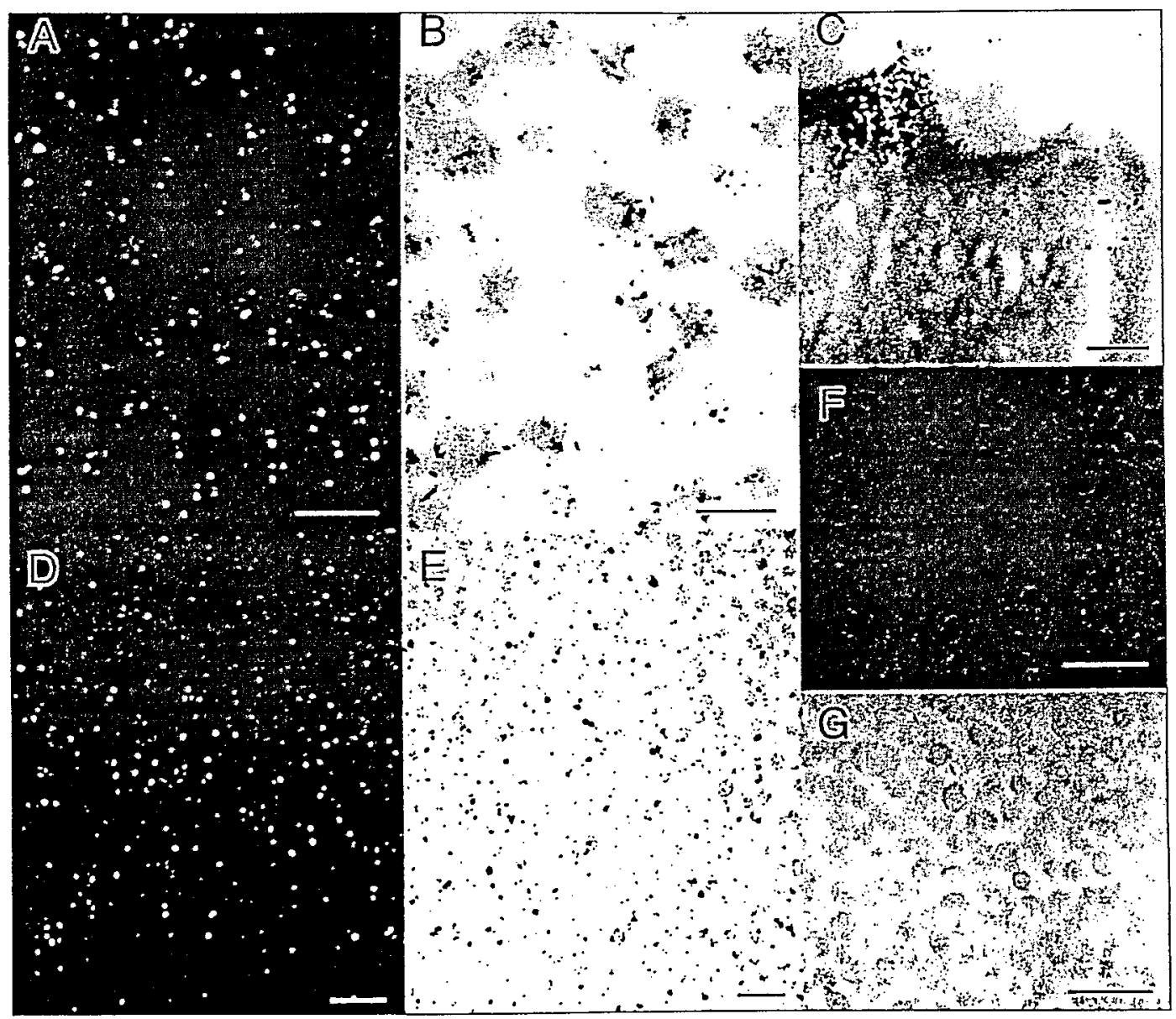

Figure 7.4. In situ hybridization for HPV-16 DNA with biotinylated tyramides and Cy3-Nanogold-labeled streptavidin. Top row: CaSki cells $(A)$ Fluoresecnce $($ bar $=20 \mu \mathrm{m})$, (B) Light micrograph after gold AMG (bar $=10 \mu \mathrm{m})$, (C) Electron micrograph of same specimen $(\mathrm{bar}=1 \mu \mathrm{m})$. Bottom row: Silta cells by $(\mathrm{D})$ fluorescence, (E) LM after gold AMG $(\mathrm{bar}=10 \mu \mathrm{m})$, (F) fluorescence, and (G) light micrographs of control with biotin-tyramide omitted (bar $=20 \mu \mathrm{m}$ ). 
reduced or negligible for probes containing Nanogold. The probes are stable to a wide range of buffers and experimental conditions, and may therefore be used in many staining and processing protocols.

Thiols have a strong affinity towards gold and can degrade Nanogold. Therefore, thiol-containing reagents, such as dithiothreitol (DTT), should be avoided when staining with Nanogold-containing probes. If thiols must be used, concentrations should be kept below $1 \mathrm{mM}$ and exposure times kept below 10 min. In addition, some reports suggest that Nanogold may be affected by exposure to high temperatures. However, a detailed study by UV visible spectroscopy has shown that about $80 \%$ of Nanogold is still intact even after several $h$ at $100^{\circ} \mathrm{C} .15$ The risk from such conditions may be avoided by performing AMG before exposure.

When higher concentrations of the combined fluorescent and Nanogold probe are required to obtain sufficiently intense fluorescent signals, this can result in higher background signals upon silver-salt-based AMG. This may be avoided by washing thoroughly with sodium citrate buffer before enhancement. Where HQ Silver is used, $0.02 \mathrm{M}$ sodium citrate buffer at $\mathrm{pH}$ 7.0 has been found to be most effective; in preparations utilizing the Danscher silver enhancement protocol, 7 $0.02 \mathrm{M}$ sodium citrate buffer adjusted to $\mathrm{pH} 3.5$ was most effective.

In some procedures, poor development has been found upon AMG. Results may be improved by changing from commercial silver enhancement reagents to the Danscher formulation ${ }^{7}$ or Hacker's silver acetate modifications, ${ }^{12}$ or by substituting formaldehyde for glutaraldehyde in postfixation.

Combined fluorescein and Nanogold probes have sometimes shown a nonspecific affinity for nucleic acids or other nuclear materials, possibly due to the presence of the hydrophobic fluorescein in close proximity to Nanogold, which possesses similarly hydrophobic aromatic substituents, which might interact with the bases of nucleic acids. Treatment with either a detergent, such as Tween 20, or an amphiphilic reagent, such as benzamidine or 1,2,3heptanetriol, ${ }^{20}$ may reduce this effect.

Enlargement of the Nanogold by AMG might be expected to reduce the fluorescence yield, since the enlarged particle will have higher extinction coefficients. However, Robinson and Vandré have shown that short periods of silver enhancement (1-2 min), which are sufficient to render the Nanogold particles visible by EM, are tolerated, and sufficient fluorescence is retained for useful correlation of the data found by fluorescence and other optical microscopy methods. ${ }^{26}$

Combined fluorescent and Nanogold probes are only one of a number of new probes that have been made possible by the development of covalent metal cluster and nanoparticle labeling technology. Other metal clusters adapted for use as microscopy labels include $2 \mathrm{~nm}$ platinum clusters. These are larger and more readily visualized than Nanogold even without AMG. ${ }^{22}$ The smaller tetrairidium cluster has also been used in conjunction with image processing for highresolution structural studies of large protein assemblies such as viral capsids. ${ }^{5}$

Larger probe labels prepared using the same covalent cross-linking rationale used for Nanogold would possess many advantages for EM applications, and because covalent linking enables the preparation of probes containing molecules such as lipids ${ }^{1,16}$ and oligonucleotides ${ }^{2}$ as well as the antibodies and proteins used for colloidal gold conjugation, it would expand the range of probes available. We have recently prepared a covalently linked 10 $\mathrm{nm}$ gold probe, and this was successfully used to label the proteins that make up the polar tube apparatus in microsporida 
spores. ${ }^{11}$ Further development of this technology is currently in progress, and it is hoped that such probes will be made available commercially in the future.

\section{ACKNOWLEDGMENTS}

We are grateful to Dr. D.L. Spector, S. Kaurin, and J. McCann of Cold Spring Harbor Laboratory for developing Protocol 1 for cellular labeling and for helpful discussions in resolving background issues. I am also grateful to Drs. G.W. Hacker, C. Hauser-Kronberger (both Salzburg), and A.L.M. Cheung (Hong Kong) for the in situ hybridization protocols. This work was supported by the Office of Biological and Environmental Research of the US Department of Energy under Prime Contract No. DE-AC02-98CH10886 with Brookhaven National Laboratory by National Institutes of Health Grant 2P41RR61777 and by Small Business Innovation Research Grant Nos. GM48328, GM56090, and GM60067 from the National Institute of General Medical Sciences, National Institute of Health.

\section{REFERENCES}

1.Adler-Moore, J. 1994. AmBisome targeting to fungal infections. Bone Marrow Transplant. 14:S3-S7.

2.Alivisatos, A. P., K.P. Johnsson, X. Ping, T.E. Wilson, C.). Loweth, M.P. Bruchez, Jr., and P.G. Schultz. 1996. Organization of 'nanocrystal molecules' using DNA. Nature 382:609-611.

3.Behnke, O, T. Ammitzboll, H. Jessen, M. Klokkker, K. Nilausen, J. Tranum-Jensen, and L. Olsson. 1986. Non-specific binding of protein-stabilized gold sols as a source of error in immunocytochemistry. Eur. J. Cell Biol. 41:326-338.

4.Bernhard, W. 1969 . A new staining procedure for electron microscopical cytology. J. Ultrastruct. Res. 27:250-265.

5.Cheng, N., J.F Conway, N.R. Watts, J.F. Hainfeld, V. Joshi, R.D. Powell, S.J. Stahl, P.E. Wingfield, and A.C. Steven. 1999. Tetrairidium, a 4-atom cluster, is readily visible as a density label in $3 \mathrm{I}$ ) cryo- $\mathrm{EM}$ maps of proteins at 10-25 $\AA$ resolution. J. Struct. Biol. 127:169-176.
6.Danscher, G. 1981. Histochemical demonstration of heavy metals. A revised version of the silver sulphide method suitable for both light and electron microscopy. Histochemistry 71:1-16.

7.Danscher, G. 1981. Localization of gold in biological tissuc. A photochemical method for light and electron microscopy. Histochemistry 71:81-88.

8.Forster, Th. 1948. Zwischenmolekulare Energiewandung und Fluoreszenz. Ann. Physik. 2:55-75.

9.Fu, X.-D. and T. Maniatis. 1990. Factor required for mammalian spliceosome assembly is localized to discrete regions in the nucleus. Nature 343:437-441.

10.Gilerovitch, H.G., G.A. Bishop, J.S. King, and R.W. Burry. 1995. The use of electron microscopic immunocytochemistry with silver-enhanced 1.4-nm gold particles to localize GAD in the cerebellar nuclei. J. Histochem. Cytochem. 43:337-343.

11.Gutierrez, E., R.D. Powell, J.F. Hainfeld, and P.M. Takvorian. 1999. A covalently linked $10 \mathrm{~nm}$ gold immunoprobe, p. 1324-1325. In G.W. Bailey, W.G. Jerome, S. McKernan, J.F. Mansfield, and R.L. Price (Eds.), Proc. 57th Ann. Mtg., Micros. Soc. Amer. Springer-Verlag, New York.

12.Hacker, G.W., C. Hauser-Kronberger, I. Zehbe, H. Su, A. Schiechl, O. Dietze, and R. Tubbs. 1997. In situ localization of DNA and RNA sequences: supersensitive in situ hybridization using streptavidinNanogold-silver staining: minireview, protocols, and possible applications. Cell Vision 4:54-65.

13. Hainfeld, J.F. 1990. STEM analysis of Janssen Auroprobe One, p. 954. In G.W. Bailey (Ed.), Proc. XII Int. Cong. Elec. Microsc. San Francisco Press, San Francisco.

14.Hainfeld, J.F. and F.R. Furuya. 1992. A. 1.4-nm gold cluster covalently attached to antibodies improves immunolabeling. J. Histochem. Cytochem. 40:177184.

15.Hainfeld, J.F. and E.R. Furuya. 1995. Silver enhancement of Nanogold and undecagold, p. 71-96. In M.A. Hayat (Ed.), Immunogold-Silver Staining: Principles, Methods, and Applications. CRC Press, Boca Raton.

16.Hainfeld, J.F., F.R. Furuya, and R.D. Powell. 1999. Metallosomes. J. Struct. Biol. 127:152-160.

17.Hainfeld, J.E and R.D. Powell. 1997. Nanogold technology: new frontiers in gold labeling. Cell Vision 4:408-432.

18.Hainfeld, J.F., R.D. Powell, J.K. Stein, G.W. Hacker, C. Hauser-Kronberger, A.L.M. Cheung, and C. Schöfer. 1997. Gold-based autometallography, p. 486487. In G.W. Bailey, W.G. Jerome, S. McKernan, J.F. Mansfield, and R.L. Price (Eds.), Proc. 57th Ann. Mtg., Micros. Soc. Amer. Springer-Verlag, New York.

19.Kramarcy, N.R. and R. Sealock. 1990. Commercial preparations of colloidal-gold-antibody complexes frequently contain free active antibody. J. Histochem. Cytocliem. 39:37-39.

20.Michel, H. 1991. Crysallization of Membrane I'rotcins. CRC Press, Boca Raton.

21.Powell, R.D., C.M.R. Halsey, and J.F. Hainfeld. 1998. Combined fluorescent and gold immunoprobes: reagents and methods for correlative light and electron microscopy. Micros. Res. Tech. 42:2-12. 
22.Powell, R.D., C.M.R. Halsey, W. Liu, V.N. Joshi, and J.F. Hainfeld. 1999. Giant platinum clusters: $2 \mathrm{~nm}$ covalent metal cluster labels. J. Struct. Biol. 127:177184.

23.Powell, R.D., C.M.R. Halsey, D.L. Spector, S.L. Kaurin, J. McCann, and J.E. Hainfeld. 1997. A covalent fluorescent-gold immunoprobe: simultaneous detection of a pre-mRNA splicing factor by light and electron microscopy. J. Histochem. Cytochem. 45:947956.

24.PoweII, R.D., V.N. Joshi, C.M.R. Halsey, J.F. Hainfeld, G.W. Hacker, C. Hauser-Kronberger, W.H. Muss, and P.M. Takvorian. 1999. Combined Cy3Nanogold conjugates for immunocytochemistry and in situ hybridization, p. 1324-1325. In G.W. Bailey; W.G. Jerome, S. McKernan, J.F. Mansfield, and R.L. Price (Eds.), Proc. 57th Ann. Mtg., Micros. Soc. Amer. Springer-Verlag, New York.

25.Reynolds, E.C. 1963. The use of lead citrate at high $\mathrm{pH}$ as an electron-opaque stain in electron microscopy. J. Cell Biol. 17:208-213.

26.Robinson, J.M. and D.D. Vandré. 1997. Efficient immunocytochemical labeling of leukocyte microtubules with FluoroNanogold: an important tool for correlative microscopy. J. Histochem. Cytochem. 45:631-642.

27.Segond von Banchet, G. and B. Heppelmann. 1995. Non-radioactive localization of supstance $P$ binding site in rat brain and spinal cord using peptides labeled with 1.4-nm gold particles. J. Histochem. Cytochem. 43:821-827.

28.Sun, X.J., L.P. Tolbert, and J.G. Hildebrand. 1995. Using laser scanning confocal microscopy as a guide for electron microscopic study: a simple method for correlation of light and electron microscopy. J. Histochem. Cytochem. 43:329-335.

29. Takizawa, T. and J.M. Robinson. 1994. Use of 1.4$\mathrm{nm}$ immunogold particles for immunocytochemistry on ultra-thin cryosecrions. J. Histochem. Cytochem. 42:1615-1623.

30.Takizawa, T., K. Suzuki, and J.M. Robinson. 1998. Correlative microscopy using FluoroNanogold on ultrathin cryosections: proof of principle. J. Histochem. Cytochem. 46:1097-1102.

31.Vandré, D.D. and R.W. Burry. 1992. Immunoelectron microscopic localization of phosphoproteins associated with the mitotic spindle. J. Histochem. Cytochem. 40:1837-1847.

32.Zehbe, I., G.W. Hacker, H. Su, C. Hauser-Kronberger, J.F. Hainfeld, and R. Tubbs. 1997. Sensitive in situ hybridization with catalyzed reporter deposition, streptavidin-Nanogold, and silver acetate automerallography. Detection of single-copy human papilloma virus. Am. J. Pathol. 150:1553-1561. 